\title{
Article \\ Exploiting Agronomic and Biochemical Traits to Develop Heat Resilient Cotton Cultivars under Climate Change Scenarios
}

\author{
Muhammad Mubashar Zafar 1,2,3, Abdul Manan ${ }^{3}{ }^{(D)}$, Abdul Razzaq ${ }^{2}$, Misbah Zulfqar ${ }^{4}$, Asif Saeed ${ }^{3}$, \\ Muhammad Kashif ${ }^{3}$, Azeem Iqbal Khan ${ }^{3}$, Zareen Sarfraz ${ }^{2}$ (D), Huijuan Mo 1,2, Muhammad Shahid Iqbal 2,5,*(D), \\ Amir Shakeel ${ }^{3, *}$ and Maozhi Ren ${ }^{1,2, *}$
}

check for

updates

Citation: Zafar, M.M.; Manan, A.; Razzaq, A.; Zulfqar, M.; Saeed, A.; Kashif, M.; Khan, A.I.; Sarfraz, Z.; Mo, H.; Iqbal, M.S.; et al. Exploiting Agronomic and Biochemical Traits to Develop Heat Resilient Cotton Cultivars under Climate Change Scenarios. Agronomy 2021, 11, 1885. https: / / doi.org/10.3390/ agronomy11091885

Academic Editors: Syed

Tahir Ata-Ul-Karim,

Saadatullah Malghani and Muhammad Ishaq Asif Rehmani

Received: 11 August 2021

Accepted: 15 September 2021

Published: 20 September 2021

Publisher's Note: MDPI stays neutral with regard to jurisdictional claims in published maps and institutional affiliations.

Copyright: (c) 2021 by the authors. Licensee MDPI, Basel, Switzerland. This article is an open access article distributed under the terms and conditions of the Creative Commons Attribution (CC BY) license (https:/ / creativecommons.org/licenses/by/ $4.0 /)$.
1 Zhengzhou Research Base, State Key Laboratory of Cotton Biology, Zhengzhou University, Zhengzhou 450000, China; m.mubasharzafar@gmail.com (M.M.Z.); mohuijuan86@163.com (H.M.)

2 Institute of Cotton Research, Chinese Academy of Agricultural Sciences, Anyang 455000, China; biolformanite@gmail.com (A.R.); zskpbg@hotmail.com (Z.S.)

3 Department of Plant Breeding and Genetics, University of Agriculture, Faisalabad 38000, Pakistan; abdulmanan4636@gmail.com (A.M.); drasifpbg@gmail.com (A.S.); mkashifpbg@gmail.com (M.K.); azeempbg@gmail.com (A.I.K.)

4 Oilseeds Research Institute, Ayub Agricultural Research Institute, Faisalabad 38850, Pakistan; misbahzulfqar@gmail.com

5 Cotton Research Station, Ayub Agricultural Research Institute, Faisalabad 38850, Pakistan

* Correspondence: shahidkooria@gmail.com (M.S.I.); dramirpbg@gmail.com (A.S.); renmaozhi01@caas.cn (M.R.)

\begin{abstract}
The development of high-yielding heat-tolerant cotton cultivars harboring plastic phenotypes across warming climatic regions is prime objectives of today's cotton breeding programs. We evaluated eight parents and $15 \mathrm{~F}_{1}$ hybrids under normal and heat stress conditions. Agronomic and biochemical characters were analyzed using standard least square, correlation, principal component analysis (PCA), and hierarchical clustering. The results explained a significant reduction in all traits except hydrogen peroxide contents, catalase, and peroxidase activities with a prominent increase under heat stress. A significant positive correlation was observed among all agronomic and biochemical traits. POD was found to have a maximum positive correlation with CAT (0.947) and minimum with boll weight (0.050). PCA showed first two components accounting for $78.64 \%$ of the total variation, with $55.83 \%$ and $22.80 \%$ of the total variation, respectively. Based on multivariate analyses methods 23 genotypes have been placed in 3 groups: tolerant (cluster-3), moderately tolerant (cluster-2), and susceptible (cluster-1). In a general perspective hybrids have better performance across normal and heat stress supports the idea of hybrid adaptability across stress environments. In specific FH-458 $\times$ FH-313 cross performed best across both conditions for yield and physiological traits. Hence, the generated information from the present study would support breeders in developing heat-resilient cultivars to endure the prevailing extreme environmental conditions.
\end{abstract}

Keywords: heat stress; cotton; principal component analysis (PCA); cluster analysis; heat resilience; plastic phenotype; climate change

\section{Introduction}

Cotton (Gossypium hirsutum L.) is a major source of oil and natural fiber [1]. Heat stress is the primary restraining factor affecting cotton growth and production [2]. Cotton is mainly cultivated across tropical and sub-tropical regions with temperatures ranging from 40 to $45^{\circ} \mathrm{C}$. Heat stress resulting from elevated temperature is considered a severe agricultural issue across many areas worldwide. The occurrence of elevated temperature causes an array of biological changes within plants, ultimately affecting plant growth and development, leading to a severe decline in productivity [3]. It is assumed that plant development and biomass accumulation are highly temperature-dependent across the growing season $[4,5]$. Plant response to heat stress mainly considers the peak temperature 
duration and degree [6]. Moreover, heat stress is highly correlated with water deficiency and is further exacerbated by the limited or unreliable water availability across cotton belts worldwide [7]. During the early growth of cotton, high temperatures may adversely affect crop productivity and cotton quality [8].

Different studies suggested that higher than optimal temperatures negatively impacted cotton morphology, physiology, metabolism and yield [3,9]. Brown et al. (2003) suggested that heat stress causes instability for seed cotton yield. Each $1{ }^{\circ} \mathrm{C}$ increase of temperature than the optimal temperature in the field lowers the seed cotton yield by $110 \mathrm{~kg} \mathrm{ha}^{-1}$ [10]. Heat stress at the flowering stage resulted in flower shedding and lower boll weight, leading to low cotton yield [11]. The average boll weight of cotton in hot climate areas is 2-3 g lower than other cotton-producing countries of the world [8]. Heat stress decreased the chlorophyll contents, photosynthetic rate [12,13], fruiting bodies [14], boll weight [8], seed cotton yield and fiber quality [15]. The heat stress at reproductive phases is a major constraint to attain yield potential in Pakistan. In May-June, the temperature elevated up to $47^{\circ} \mathrm{C}$, which bring about high humidity in July-August that negatively affects cotton reproductive stages [16]. Due to elevated temperature, 65 to $70 \%$ of fruiting points shed down, lowering the cotton yield [17]. In Pakistan, the high temperature at reproductive phases is a primary reason for lower seed cotton yield. It also disrupts the stomatal movement that leads to poor gaseous exchange [18]. This situation compelled the cotton breeders to develop cotton genotypes through breeding and selection, retaining more bolls under heat stress [14].

The optimum temperature for germination of cottonseed and root development is $12{ }^{\circ} \mathrm{C}$ and $30{ }^{\circ} \mathrm{C}$, respectively. For seedling development and stomatal conductance, the optimum temperature is $28-30{ }^{\circ} \mathrm{C}$, and boll development ranges between 25.5 to $29.5^{\circ} \mathrm{C}[18,19]$. A temperature higher than 25.5 to $29.5^{\circ} \mathrm{C}$ lessens the boll weight [19]. The temperature was ranging between 35 to $40{ }^{\circ} \mathrm{C}$ causes boll maintenance issues [20]. At $40{ }^{\circ} \mathrm{C}$ during the daytime, a considerable decline in the number of bolls and bolls retention was observed as well as it also disrupted fruiting periods, resulting in lower seed cotton yield [21,22]. High temperatures decrease pollen fertility, embryo abortion, and lower nutrient uptake efficiency [23]. It also negatively affects the antioxidant activities that result in decreased seed cotton yield [24]. Under heat stress, oxidative stress commonly produces reactive ROS abundantly [25]. The abundant production of ROS can damage plant cells irreversibly by the oxidation of various cellular compartments like chloroplast, peroxisomes, and mitochondria [26]. In plants, tolerance to oxidative stress is directly related to antioxidant enzymes production like superoxide dismutase (SOD), peroxidases (POD), catalase (CAT) and non-enzymatic antioxidants such as carotenoids, flavonoids and ascorbate etc. [27]. To attain the yield potential of cotton under elevated temperature stress thus, became a challenging issue [23].

The detailed knowledge about genetic variability for yield and quality-related traits in the existing germplasm of a species is a prerequisite to start a crop improvement program $[28,29]$. The development of stress-tolerant high-yielding cultivars is the primary objective of plant breeders [28,30]. Successfully hybridization for improved yield under stress conditions depends primarily on genetic diversity's nature and scale, which helps plant breeders select divergent parents [31]. Moreover, the knowledge about the nature and extent of the relationship between different agronomic, biochemical, and yield-related traits under heat stress can prove helpful in the selection of heat-tolerant cotton genotypes [15]. Generally, to speed up crop genetic improvement, genetic divergence in the existing germplasm should be approachable. From the above perspective, it is necessary to ascertain the genetic variability within genotypes and assess the available varieties under heat stress for future breeding and development of heat stress-tolerant and high-yielding cotton cultivars. So, there is a need to develop efficient strategies to characterize and evaluate available germplasm [32]. Multivariate analysis is an efficient approach to explain the degree and nature of divergence of functional characters in available germplasm. [24,33,34]. Various statistical approaches have been used in crop modeling for yield under stress 
environments, including correlation and regression analyses and factor and cluster analyses to assess yield contributing characters for breeding programs [35].

Phenotypic flexibility that implies to traits is not constant across changing climatic conditions, especially rapidly warming. In recent years, it common, as one genotype may exhibit different phenotypes due to the prevailing environmental conditions $[30,36]$. In agreement with this phenomenon, assessment of the various morphological, biochemical traits may play a major role in maintaining germplasm resources, especially in terms of capturing resources as well as its conversion towards sustainable economic yield. It can provide a strong basis for the possibility and successful future crop improvement programs [37]. It can be achieved through analyzing these traits for the assessment of existing variability between and within populations through using mathematical models including linear regression models on the one hand whereas various multivariate techniques viz. correlation, principal component analysis (PCA) and cluster analyses on the other hand. These statistical techniques have been demonstrated as the most suitable in assessing variations and can efficiently discriminate multiple individual genotypes as well as different populations even though the measured variables may or may not be considered in tandem [35,38-40].

To this end, the current study has been designed to identify suites of phenotypic and multivariate characteristics of available cotton genetic resources that may assist in developing new cultivars and contribute to the theoretical determination of the agronomical value of these genetic assets. A set of advance statistical procedures including least square fit and multivariate analysis techniques including correlation, principal component analysis (PCA) and cluster analyses have been utilized for the discrimination and grouping of heat tolerant and susceptible accessions for further selection. This kind of base information undoubtedly can outline the possibility of contribution in the existing pool of natural variability in economically important traits in cotton, which might be used to develop highyielding cultivars suitable for higher temperature areas and come across with significant evolutionary benefits crop can owe.

\section{Materials and Methods}

Eight cotton genotypes have been selected from a pre-screening experiment of cotton germplasm including 50 accessions for heat tolerance and already designated as tolerant and susceptible genotypes. Among them five heat-tolerant cotton genotypes (lines) and three heat-sensitive genotypes (testers) were crossed in line $\times$ tester mating design in 2018 at the experimental farm, Department of Plant Breeding and Genetics, University of Agriculture Faisalabad, Pakistan. During the next cotton growing season in June 2019, $\mathrm{F}_{1}$ seeds of 15 crosses and their parents were sown in field conditions under normal and heat stress conditions with three replications under randomized complete block design (RCBD) following by split-plot arrangement. All agronomic practices were kept constant throughout the season. The list of genotypes is given in (Table S1).

At $50 \%$ flowering, heat stress was applied in September for 12 days. By constructing a polythene tunnel, the considerable temperature was elevated in the daytime and uncovered at night [41]. During heat stress, the temperature of control and tunnel was recorded twice a day [42]. The maximum and minimum temperature was measured inside the tunnel with the help of a digital thermometer (Figure 1).

\subsection{Biochemical and Yield-Related Parameters}

After heat stress of 12 days, data were recorded for biochemical characters from five selected plants under normal and stressed conditions from each replication. Young leaves were collected from the top of the plant for biochemical analysis from each genotype. Enzyme extraction was performed with $0.5 \mathrm{~g}$ of cotton leaf sample in chilled condition with $1-2 \mathrm{~mL}$ of potassium phosphate buffer ( $\mathrm{pH}$ 7.8). The prepared mixture was then centrifuged for $5 \mathrm{~min}$ at $1400 \mathrm{rpm}$. The supernatant was used for biochemical traits quantification by using a UV spectrometer at different wavelengths. The $\mathrm{H}_{2} \mathrm{O}_{2}$ was determined by following 
the protocol proposed by [43], catalase and peroxidase by [44], and chlorophyll contents by [45]. Data regarding agronomic traits plant height $(\mathrm{cm})$, number of bolls, boll weight $(\mathrm{g})$, seed cotton yield $(\mathrm{g})$ and seed index $(\mathrm{g})$ were recorded at maturity from five randomly selected guarded plants of each accession.
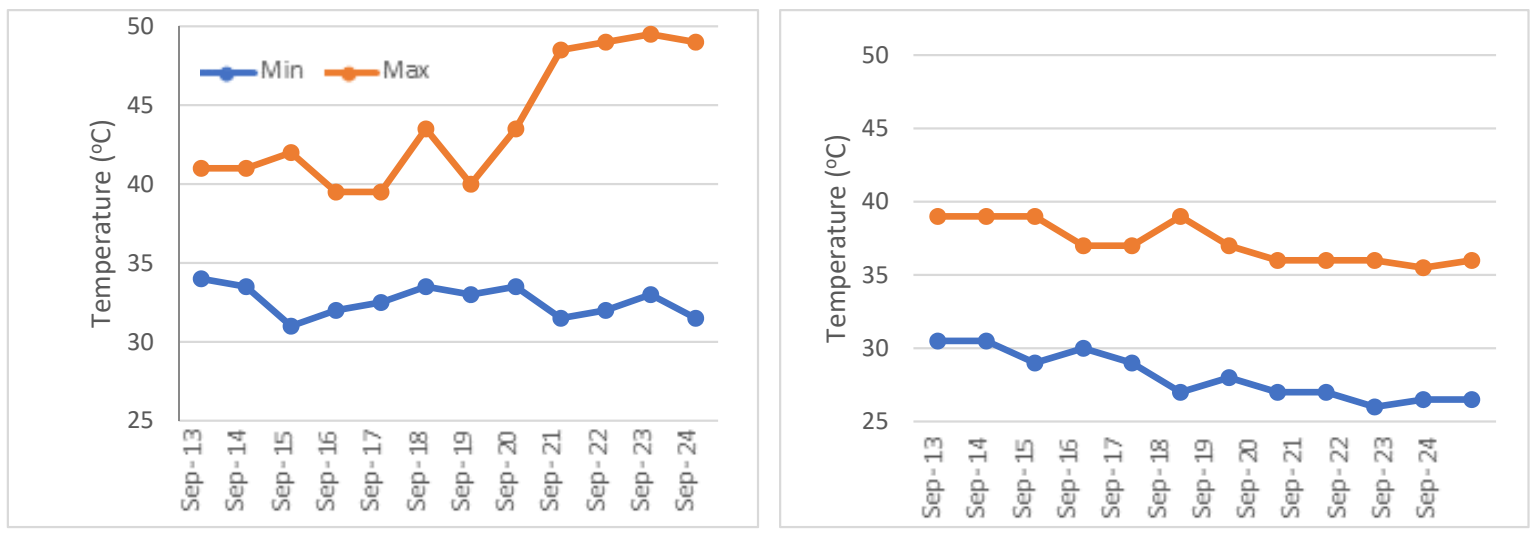

Figure 1. Mean Minimum and the maximum temperature $\left({ }^{\circ} \mathrm{C}\right)$ inside (Right) and outside (Left) tunnel during experiment.

\subsection{Statistical Analysis}

Initially, the data collected for all traits under study regarding parents have been analyzed to validate whether the parental groups (tolerant and susceptible) performed significantly differently within and across normal and heat stress conditions. For this purpose, interaction profilers were plotted using the least square fit model with the help of the statistical software package SAS-JMP Pro 16 (SAS Institute Inc., Cary, NC, USA, 1989-2011). After confirming the existence of a reasonable amount of differences among parents under normal and heat stress conditions, all collected data were subjected to standard least-square effect fit to all the variables under study, considering the replications, genotypes and treatments. The data was then averaged for replications regarding treatments and genotypes and the mean data were then subjected to multivariate analyses, including correlation, PCA, and cluster analyses. Pairwise correlations have been calculated to make a Correlogram through Pearson correlation method. The means for genotype and treatments were used for correlation-based principal component analysis using default functions for standardization/scaling by JMP software: SAS-JMP Pro 16 (SAS Institute Inc., Cary, NC, USA, 1989-2011). Cluster analysis was performed using the Hierarchical clustering approach with two-way clustering to generate a tree diagram based on Euclidean distances by Ward's method. To decide on a number of clusters, a distance graph was followed representing the threshold for selection of the number of clusters by determining when the distances between clusters no longer appear to be of practical importance. Default standardization option in JMP Pro 16 SAS-JMP Pro 16 (SAS Institute Inc., Cary, NC, USA, 1989-2021) has been selected for analysis to standardize the range of the continuous initial variables so that each one contributes equally to the analysis.

\section{Results}

Results presented as interaction profilers (Figure S1) indicated a reasonable variation among the tolerant and susceptible genotypes across normal and heat stress conditions. All studied traits have shown a varying trend for parents across different conditions (Figure S1). A sufficient amount of variation presented in results validated the hypothesis for the use of reference susceptible and tolerant parental accessions to be included for the current study.

After initial validation, the standard least-square effects fit applied on all test accessions across different conditions revealed that all genotypes performed sigSuppnificantly differently for studied characters under normal and heat stress conditions (Tables S2-S10). Summary of effect tests as presented in Table 1 and Figure 2 indicating the least square effects of heat 
stress on all parents and their hybrids were significant regarding all studied traits. The genotype $\times$ treatment interaction was also significant for all studied traits (Table 1 ).

The correlation analysis was performed to assess the relationship among nine agronomical and biochemical traits. The Correlogram showed scatter plot, variable distribution and correlation coefficient. Overall, the combined correlation coefficient revealed that the $\mathrm{PH}, \mathrm{TNB}$ and chlorophyll contents have a significant negative relationship with $\mathrm{H}_{2} \mathrm{O}_{2}, \mathrm{POD}$ and CAT. The SCY and BW positively correlated with $\mathrm{PH}, \mathrm{TNB}$, chlorophyll contents (a \& b), while negatively associated with CAT. The SCY also exhibited a negative association with POD. The POD and CAT both revealed a significant negative association with $\mathrm{H}_{2} \mathrm{O}_{2}$ (Figure 3). The plants responded to increased $\mathrm{H}_{2} \mathrm{O}_{2}$ by up-regulating defensive enzymes activities such as POD and CAT to metabolize $\mathrm{H}_{2} \mathrm{O}_{2}$. Under heat stress, the box plots showed that $\mathrm{H}_{2} \mathrm{O}_{2}$ contents, CAT and POD activities were increased, but $\mathrm{PH}, \mathrm{TNB}, \mathrm{BW}$, SCY and chlorophyll contents were decreased and revealed a negative association with $\mathrm{H}_{2} \mathrm{O}_{2}$, CAT and POD. The prediction profiler plot was also used to find out the most desirable genotypes for both environments. The desirability graph showed that the genotype FH-458 $\times$ FH-313 performed well as compared to all other genotypes for agronomical and biochemical traits under both conditions (Figure 3).
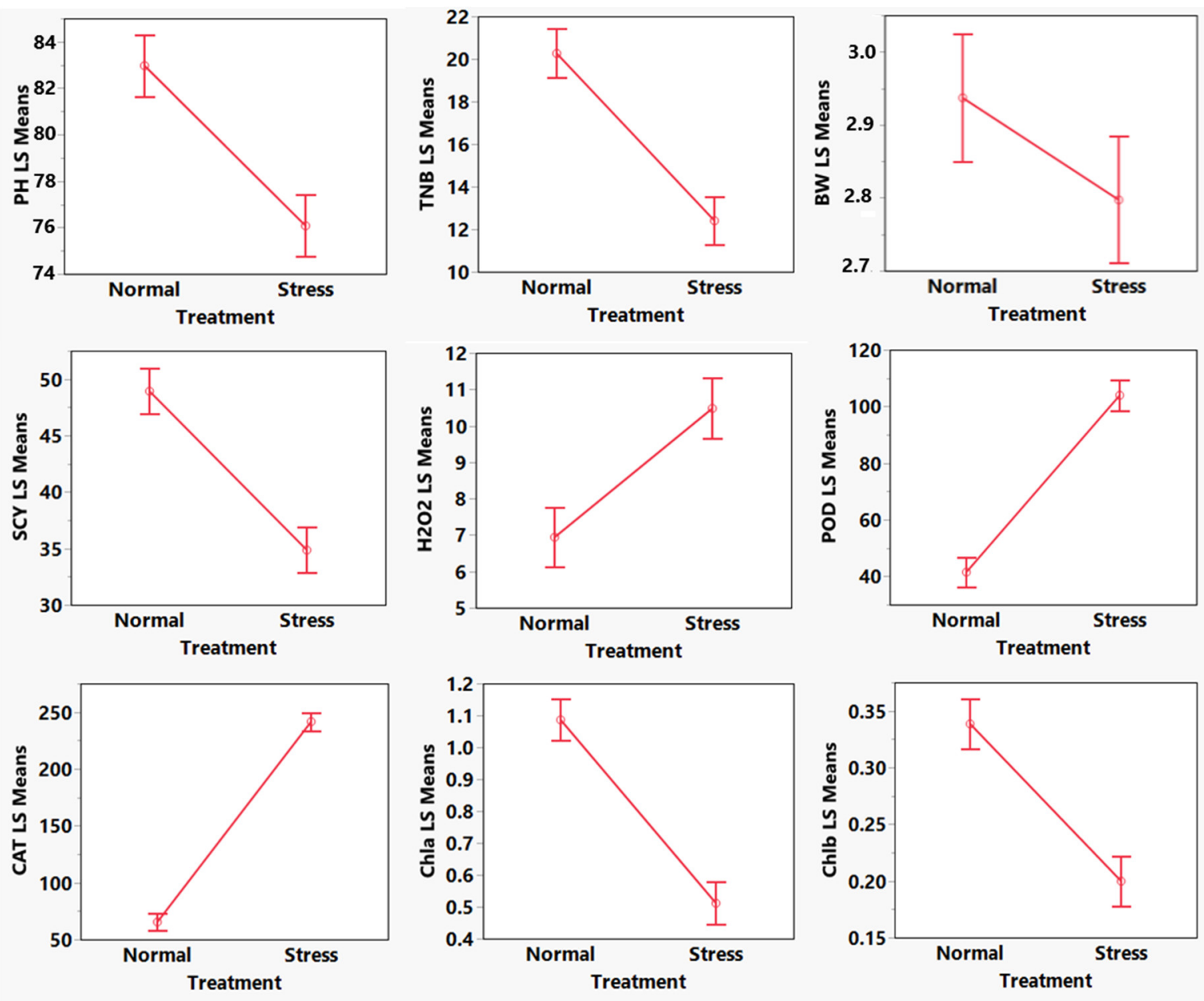

Figure 2. The least square mean plots for nine studied traits representing a comparison of variables across Normal and Heat stress conditions. The mean plots are depicting spectacular differences regarding traits performance under both conditions. 
Table 1. Summary of standard least-square effect test for different agronomic and biochemical traits in cotton accession under normal and heat stress conditions.

\begin{tabular}{|c|c|c|c|c|}
\hline \multicolumn{2}{|c|}{ Traits Source } & Genotype & Treatment & $\begin{array}{l}\text { Genotype * } \\
\text { Treatment }\end{array}$ \\
\hline \multicolumn{2}{|c|}{ Nparm } & 22 & 1 & 22 \\
\hline \multicolumn{2}{|c|}{ DFNum } & 22 & 1 & 22 \\
\hline \multirow[t]{2}{*}{$\mathrm{PH}$} & F Ratio & 14.2846 & 106.3898 & 1.8302 \\
\hline & Prob > F & $<0.0001$ * & $<0.0001^{*}$ & $0.0429 *$ \\
\hline TNB & Prob $>$ F & $<0.0001$ * & $<0.0001 *$ & $0.0002 *$ \\
\hline \multirow{2}{*}{ BW } & F Ratio & 8.9352 & 12.5570 & 2.2602 \\
\hline & Prob $>F$ & $<0.0001^{*}$ & 0.0009 * & 0.0102 * \\
\hline \multirow{2}{*}{ SCY } & F Ratio & 21.8997 & 426.5928 & 4.1679 \\
\hline & Prob $>$ F & $<0.0001 *$ & $<0.0001 *$ & $<0.0001 *$ \\
\hline \multirow{2}{*}{$\mathrm{H}_{2} \mathrm{O}_{2}$} & F Ratio & 9.6527 & 98.0262 & 2.4577 \\
\hline & Prob $>$ F & $<0.0001$ * & $<0.0001^{*}$ & 0.0053 * \\
\hline POD & $\begin{array}{l}\text { F Ratio } \\
\text { Prob }>\text { F }\end{array}$ & $\begin{array}{c}34.9447 \\
<0.0001 *\end{array}$ & 5496.441 & 18.7102 \\
\hline \multirow{2}{*}{ CAT } & F Ratio & 54.9865 & 16325.80 & 15.0780 \\
\hline & Prob $>$ F & $<0.0001$ * & $<0.0001$ * & $<0.0001$ * \\
\hline \multirow{2}{*}{ Chla } & F Ratio & 20.3758 & 1484.163 & 8.9729 \\
\hline & Prob $>F$ & $<0.0001$ * & $<0.0001 *$ & $<0.0001$ * \\
\hline \multirow{2}{*}{ Chlb } & F Ratio & 16.6234 & 559.5363 & 6.4504 \\
\hline & Prob $>$ F & $<0.0001 *$ & $<0.0001$ * & $<0.0001$ * \\
\hline
\end{tabular}

* Significance $(\alpha=0.05)$.

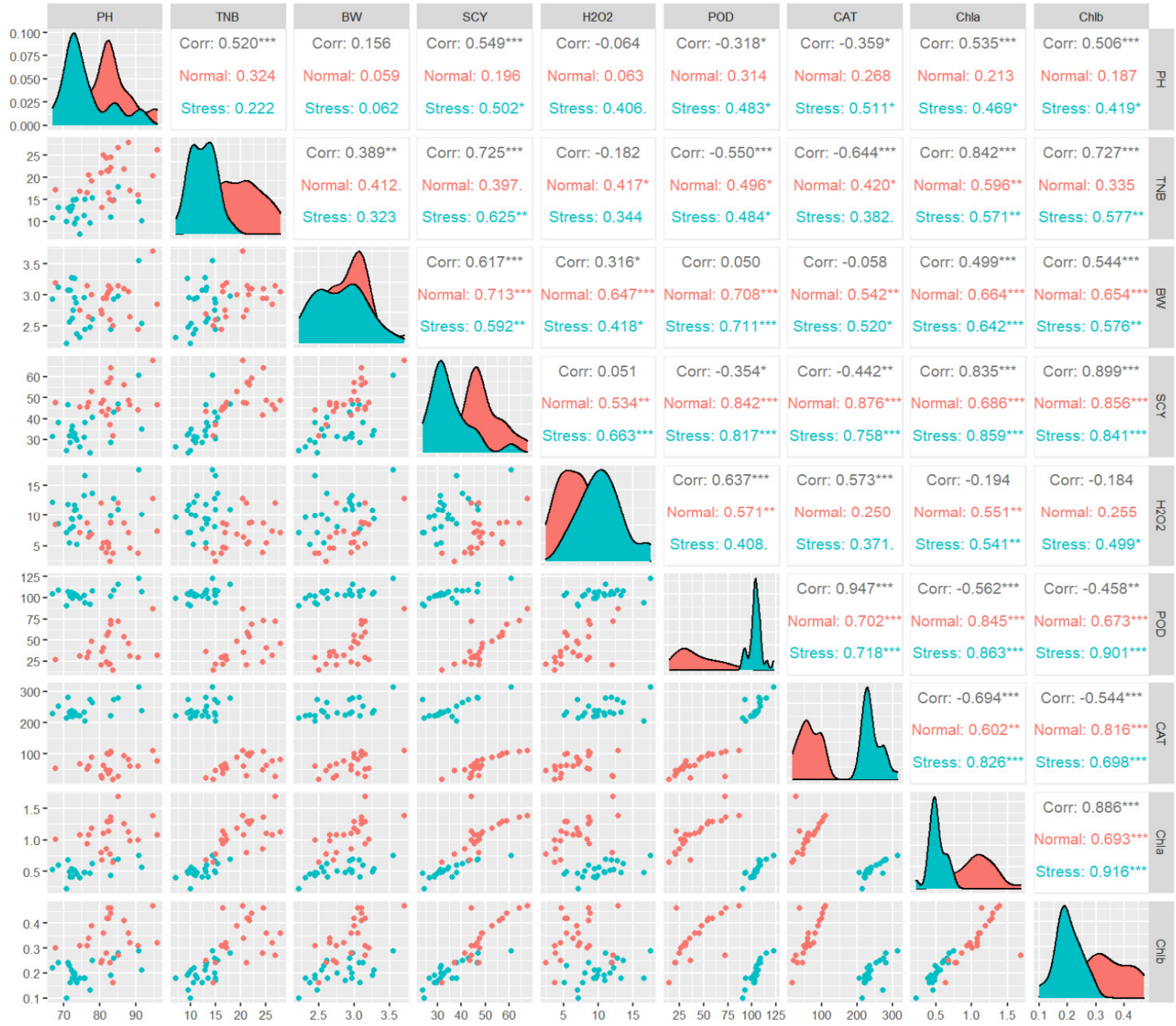

Figure 3. Correlogram depicting correlations among nine studied traits across Normal and Heat stress conditions in the upper triangle and their scatterplot matrix in the lower triangle. Diagonals are the density distribution of the study traits-the Red Color represents Normal, whereas the green color represents Heat Stress conditions. ${ }^{*}=$ Significance $(\alpha=0.05),{ }^{* *}=$ Significance $(\alpha=0.01),{ }^{* *}=$ Significance $(\alpha=0.001)$. 


\section{Cluster Analysis}

Hierarchical clustering analysis was executed to clusters the 8 parents and their 15F1 hybrid based on agronomical and ionic traits under normal and heat stress conditions. Under normal conditions, 23 genotypes were clustered into 3 groups. Groups 1, 2 and 3 consists of 12, 3 and 8 genotypes, respectively (Figure 4 ). Under heat stress, 23 genotypes were also clustered in 3 groups. Group 1, 2 and 3 contained 7, 12 and 4 genotypes, respectively (Figure 4). Under normal and heat stress conditions, different clusters were represented by different colors. Generally, the genotypes of cluster 3 have shown unchanged agronomic performance along with unchanged or higher values of biochemical traits across normal and stress conditions have been designated as heat tolerant. The second cluster have shown a nominal decrease in agronomic traits along with increased biochemical performance have been denoted as moderately tolerant. The third cluster with red color based on declined agronomic performance along with a decreased biochemical performance under stress have been designated as susceptible. Based on clustering, under normal and heat stress conditions, among parents and their hybrids, NIAB-1048 $\times$ FH-313, VH-329, NIAB-1048, IUB-65 $\times$ CRS-2, and FH-458 $\times$ FH-313 were superior genotypes for most of the studied traits. The cluster analysis also validated the prediction of desirability plots and showed that FH-458 $\times$ FH-313 performed well in yield and physiological traits under both conditions. The genotypes in obtained clusters under both conditions are given in (Table S11).
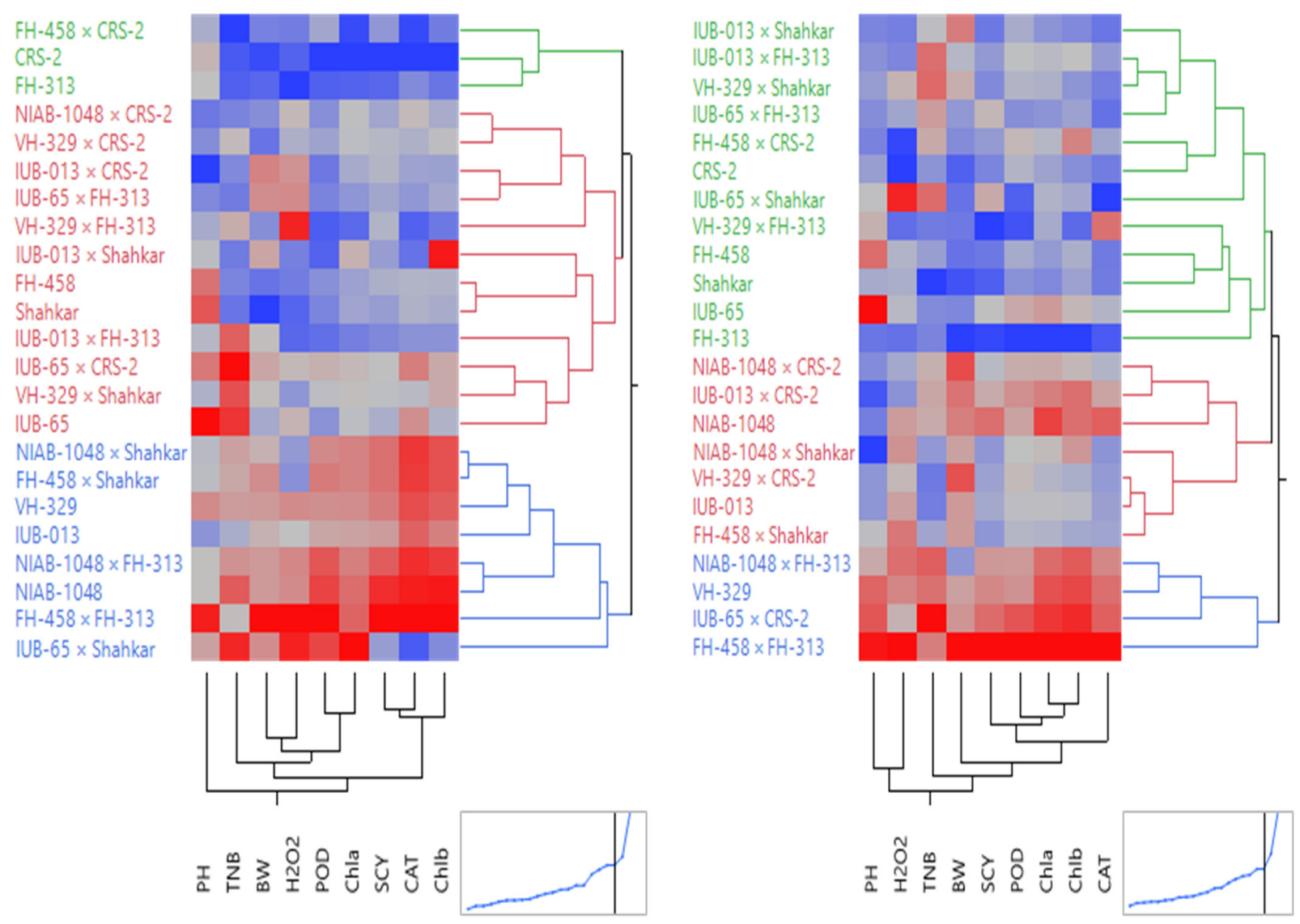

Figure 4. Hierarchical cluster of 23 cotton genotypes for biochemical and yield-related traits (left) normal and (Right) Heat stress conditions. Different colors (Red, Blue, Green) representing the groups of genotypes based on their performance. Distance graphs below the cluster diagrams are representing the threshold to decide number of possible clusters. 


\section{Principal Component Analysis (PCA)}

PCA is a multivariate statistical approach to examine complex and large datasets. Based on the association among the studied characters and extracted clusters, the variation pattern in cotton genotypes was also examined by PCA to determine the relationship between different variables that lead to variability in studied data. Under normal and heat stress conditions, 9 PCs were found, and from these 9 PCs, 3 PCs had shown commutative variation $>80 \%$ (Table S12). Hence dividing explainable variation into 3 PCs and it validates 3 groups already suggested by AHMC clustering method. These 3 PCs shared $86.93 \%$ of the total variability, while the rest of all PCs contribute $13.07 \%$ to the total variability. The PC1 had (55.83\%), followed by PC2 (22.81\%), PC3 (8.29\%), PC4 (4.55\%), and PC5 (3.41\%) variability among the genotypes for studied traits, respectively (Figure 5).

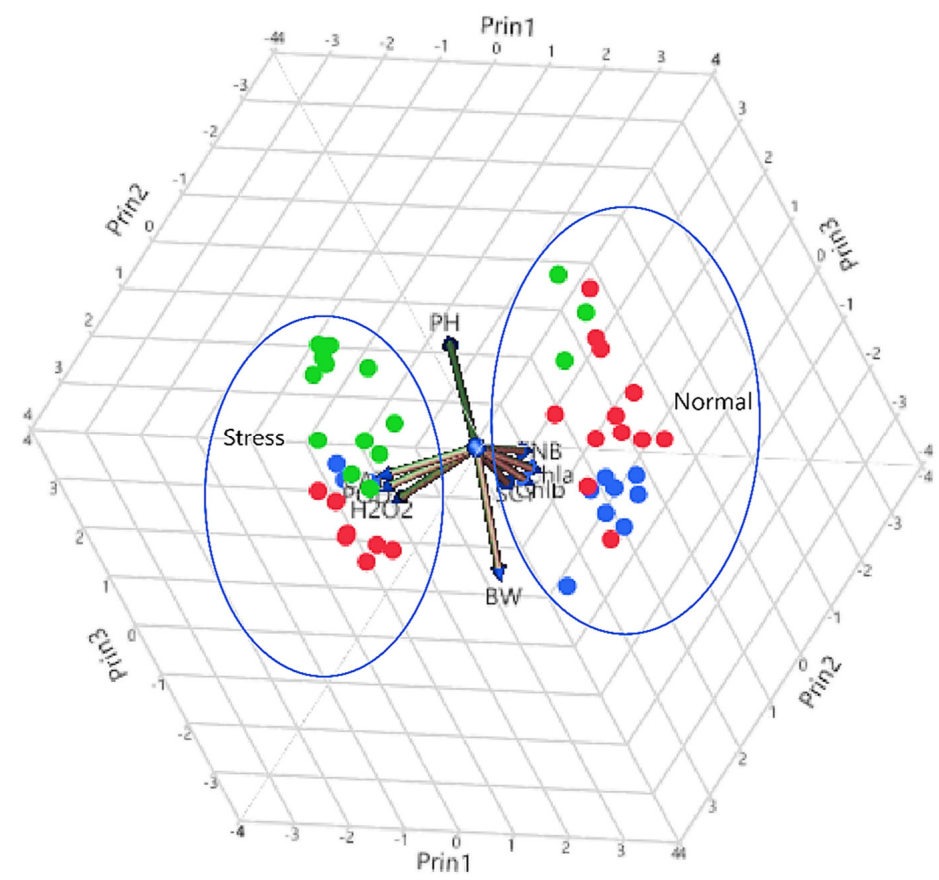

Figure 5. A 3D Scatterplot based on PC1, PC2, and PC3 displays different traits under normal and heat stress. Blue, green and red dots are representing three different groups of genotypes based on clustering as well as PCA across normal and heat stress.

Among all studied traits in cotton genotypes, the Chla (0.95) followed by Chlb (0.90), TNB (0.87), SCY (0.86), PH (0.62) and BW (0.46) were the major contributing traits to the total observed variability in PC1. The PC2 was characterized by $\mathrm{H}_{2} \mathrm{O}_{2}(0.81), \mathrm{BW}(0.70)$, POD (0.62), CAT (0.53), and SCY (0.40) (Figure 5). In biplot, traits were depicted in the form of vectors. The relative distance of the traits from origin revealed their contribution to the total variation. A PCA biplot analysis could select characters classified into main sets and subsets based on similarity and dissimilarity. In our data set, two groups of traits were identified in the PCA biplot considering PC1 and PC2. The PC-I and PC-II explained $78.64 \%$ of the total variation. The Chla, Chlb, SCY, TNB and PH had long vectors and exhibited higher variation. The characters Chla, Chlb, SCY, and TNB lay close to each other in the direction of PC1; clustered in group I and exhibited higher association.

Interestingly the $\mathrm{H}_{2} \mathrm{O}_{2}$, POD and CAT lied close to each other towards the direction of PC2; they clustered in group II and revealed a high correlation among themselves. Interestingly, the PCA biplot revealed that group I traits, the major contributors in PC1, were strongly associated with cluster 3, while the traits of group II, the contributors in PC1, were associated with the genotypes of cluster 3 . The biplot of PC1 and PC2 showed that the genotypes FH-458 $\times$ FH-313 and IUB-65 $\times$ CRS-2 are superior genotypes for studied traits. 
The biplot of PC1 and PC3 explained $64.09 \%$ variability of the total variability. In the biplot of PC1 and PC3, the traits Chla, Chlb, SCY, and TNB are more discriminating traits and significantly correlated. This biplot showed that the FH-458 $\times$ FH-313, IUB$65 \times$ CRS-2 and NIAB-1048 $\times$ FH-313 are the most desirable genotypes. The biplot of PC2 and PC3 exhibited the least variability (31.09\%) than the biplot of PC1 with PC2 and PC3 independently. In the biplot of PC2 and PC3, CAT, POD and $\mathrm{H}_{2} \mathrm{O}_{2}$ were more discriminating traits and positively correlated among themselves (Figure 5).

The PCA results showed that the first three components explained $86.931 \%$ variability to the total variation. The yield and biochemical characters are illustrated by factor map squared cosines (Figure 6). It is deduced that the higher values of squared cosines offer an adequate contribution to the particular variable. The PC-I covered TNB, SCY, POD, CAT and chlorophyll contents (a \& b). PC-II covers the traits like BW and $\mathrm{H}_{2} \mathrm{O}_{2}$. The PC3 only contained PH. The treatment effects also fell in PC1. The genotype IUB-65 $\times$ CRS-2 and VH-329 $\times$ FH-313 were covered by PC-1. The genotype CRS-2, FH-313, FH-458 $\times$ CRS-2, FH-458 $\times$ FH-313, FH-458 $\times$ Shahkar, IUB-013 $\times$ FH-313, NIAB-1048, NIAB-1048 $\times$ FH-313, VH-329 and Shahkar were covered by PC-2 and the rest of all genotypes were fell in PC3 (Figure 6).
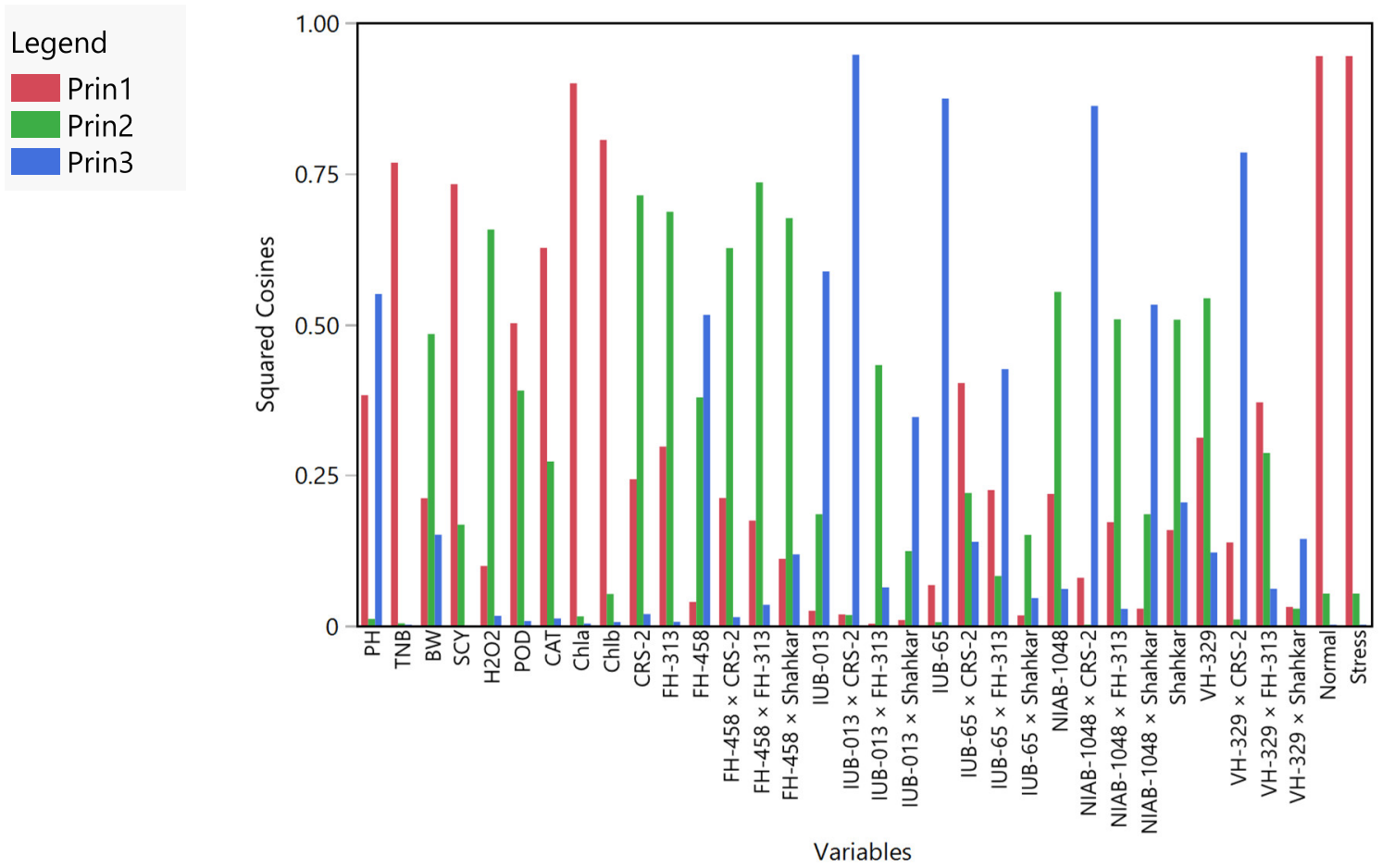

Figure 6. Squared cosines are associated with the studied traits' principal components and 23 genotypes under normal and heat stress conditions.

\section{Discussion}

Genetic diversity in germplasm allows the plant breeders to select favorable traits for developing new cotton cultivars conferring resistance to abiotic and biotic stresses. In recent years, cotton yield is decreasing alarmingly due to heat stress in hot climatic regions. Heat stress at reproductive phases alters cotton morphology and physiology, greatly reducing yield [10]. Significant effects of heat stress were observed in all genotypes for studied traits. This study observed a significant reduction in PH, TNB, BW, SCY and chlorophyll contents under heat stress $[24,46,47]$ while $\mathrm{H}_{2} \mathrm{O}_{2}$, POD and CAT activities were increased. These results align with the previous findings $[8,11]$. Under heat stress, the increased production of $\mathrm{H}_{2} \mathrm{O}_{2}$ contents causes oxidative stress and results in electrolyte leakages [47]. All the studied traits revealed significant correlations in our study, which 
suggested that change in any one of those characters correspondingly changes the other characters. It indicated that cotton's morpho-physiological traits play an important role under heat stress conditions to determine high temperature response. It means that if one reliable trait is picked in heat stress and used as a selection criterion that will lead to affect other traits under heat stress conditions.

Different studies reported that the chlorophyll contents measurement is an important marker for identifying the tolerant genotypes in a stress breeding program and suggested that the higher levels of chlorophyll content are associated with heat tolerance $[48,49]$. In our study, chlorophyll contents revealed a strong positive association with TNB, BW and SCY. Reduction in chlorophyll contents under heat stress can be attributed to increased production of $\mathrm{H}_{2} \mathrm{O}_{2}$. The significant negative correlation between chlorophyll contents and $\mathrm{H}_{2} \mathrm{O}_{2}$ established the oxidative stress-induced decrease in chlorophyll synthesis under heat. So, the reduction in chlorophyll contents is associated with decreased SCY. The heat stress destabilizes the photosynthesis process due to the excessive production of reactive oxygen species that speeds up the oxygen-induced cellular damage [50]. Due to heat stress, plants lose their cellular homeostasis by producing reactive oxygen species (ROS) [51]. The plant responded to ROS by up-regulating antioxidants defensive enzymes such as peroxidase (POD) and catalase (CAT) to metabolize ROS [52]. Peroxidase (POD) detoxifies $\mathrm{H}_{2} \mathrm{O}_{2}$ inside the cytosol and chloroplasts of the plant cells [53]. The catalase (CAT) converts the toxic $\mathrm{H}_{2} \mathrm{O}_{2}$ into water and oxygen. In this study, with the rise of temperature, $\mathrm{H}_{2} \mathrm{O}_{2}$ production increased; however, due to the scavenging activity of catalase, its negative effects were averted, as reported in the earlier findings [54]. The CAT and POD activities were higher under heat stress conditions as compared with the control condition. Previous reports have also observed a high level of CAT activity in cotton leaves under heat stress conditions [46]. The genotypes exhibiting a higher level of POD and CAT were found to be optimal for $\mathrm{H}_{2} \mathrm{O}_{2}$ and declared as heat-tolerant [47]. The correlation analysis revealed that the SCY was positively correlated with TNB, BW, POD, CAT, and chlorophyll contents (a \& b) under normal and heat stress conditions. Our results were in accordance with reported research previously by different studies [55-57].

Cluster analysis was performed to explore the genetic variation among 23 cotton genotypes for biochemical and yield-related traits, leading to breeding programs [58]. Hierarchical cluster analysis revealed that genotypes of cluster 3 have the highest ability to tolerate heat stress as judged by almost all studied traits. Our PCA results covering $86.93 \%$ of total variation in first three PCs for yield, yield contributing traits, fiber quality traits, and biochemical traits. It can affirm that discrimination of cotton genotypes can be made across the experimental conditions based on this information. Moreover, these selected varieties can also be further utilized in the cotton breeding program against heat stress. Many scientists have confirmed the presence of genetic diversity in plants species through this efficient statistical technique. Our PCA results agreed with other researchers who used this technique to find variability in cotton germplasm [59-61]. We observed that the first two PCs added maximum variation existent in experimental material. It was inconsistent with previous reports [62,63]. Under both conditions, among all studied traits in cotton genotypes, TNB, SCY, POD, CAT and chlorophyll contents $(\mathrm{a} \& \mathrm{~b})$ were the major contributing traits observed in PC1. The PC2 was characterized by BW and $\mathrm{H}_{2} \mathrm{O}_{2}$ [64]. This technique could help exploit and conserve the germplasm by dividing genetic variability into different components and being used in future breeding programs to increase the efficiency of specific traits. Our results showed that clustering of cotton genotypes varying across heat stress tolerance based on the hierarchical clustering have been validated and confirmed through the results obtained from PCA. Altogether, it is evident that 23 cotton genotypes exhibited significant variation in the heat stress changes in studied traits and the multivariate analyses could be effectively used for the identification of the cotton genotypes of desirable traits for heat tolerance.

Depending upon clustering, under normal and heat stress conditions, among parents and their hybrids, NIAB-1048 × FH-313, VH-329, NIAB-1048, IUB-65 $\times$ CRS-2, and 
FH-458 $\times$ FH-313 were superior genotypes for most of the studied traits. Different studies revealed that heat-tolerant species exhibited higher antioxidant enzyme activities in response to heat stress, while heat-sensitive species could not do so. The facts accumulated from data revealed that plants' intrinsic antioxidant resistance system might lay out a strategy to increase heat tolerance.

\section{Conclusions}

The constantly warming surroundings of every organism make them change their phenotypes accordingly for their endurance. The rapidly changing environmental conditions across the globe are enabling every genotype to make certain changes in its genome to transcribe subsequent related phenotypes. To sustain these fluctuations, there is a need to hunt for such genotypes in the available genetic stock of cotton and every other crop. keeping in context, the study was conducted to explore the heat resilient genotypes from available assets. The current research results revealed the substantial impacts of heat stress on available cotton genetic resources regarding agronomic and biochemical traits. Based on different biometrical approaches, we found that the genotype FH-458 $\times$ FH-313 performed superior to the rest of the experimental genotypes under normal and heat stress conditions. This genotype could efficiently be utilized in future cotton improvement programs to enhance heat stress endurance in high-yielding cultivars to sustain abrupt climatic calamities.

Supplementary Materials: The following are available online at https:/ / www.mdpi.com/article/10.3 390/agronomy11091885/s1, Figure S1: Interaction profiler for preliminary performance comparison of tolerant and susceptible parents across normal and stress conditions. Table S1: List of accessions used for evaluation across normal and heat stress conditions. Table S2: Detailed effect report for parameter estimates related to Plant Height under normal and heat stress conditions. Table S3: Detailed effect report for parameter estimates related to TNB under normal and heat stress conditions. Table S4: Detailed effect report for parameter estimates related to Boll weight under normal and heat stress conditions. Table S5: Detailed effect report for parameter estimates related to Seed Cotton Yield under normal and heat stress conditions. Table S6: Detailed effect report for parameter estimates related to $\mathrm{H}_{2} \mathrm{O}_{2}$ under normal and heat stress conditions. Table S7: Detailed effect report for parameter estimates related to POD under normal and heat stress conditions. Table S8: Detailed effect report for parameter estimates related to CAT under normal and heat stress conditions. Table S9: Detailed effect report for parameter estimates related to Chlorophyll-A under normal and heat stress conditions Table S10: Detailed effect report for parameter estimates related to Chlorophyll-B under normal and heat stress conditions. Table S11: Distribution of cotton genotypes in different clusters based on studied traits. Table S12: Eigen Values for different Morphological, Fiber quality and biochemical traits across normal and salt stress conditions.

Author Contributions: Conceptualization, A.S. (Amir Shakeel) and M.R.; methodology, M.M.Z., A.M., M.Z. and A.R.; software, M.S.I., Z.S. and A.S. (Amir Shakeel); validation, M.M.Z., A.I.K., Z.S., A.S. (Asif Saeed) and A.S. (Amir Shakeel); formal analysis, M.M.Z., Z.S., M.S.I. and M.Z.; investigation, M.M.Z., A.M. and M.K.; resources, A.S. (Amir Shakeel) and M.R.; data curation, M.M.Z., A.R. and H.M.; writing-original draft preparation, M.M.Z. and M.S.I.; writing-review and editing, A.S. (Amir Shakeel), A.S. (Asif Saeed), M.K., H.M., Z.S., A.I.K., A.R. and M.R.; visualization, M.S.I. and M.M.Z.; supervision, A.S. (Amir Shakeel) and M.R.; project administration, A.S. (Amir Shakeel) and M.R.; funding acquisition, M.R. All authors have read and agreed to the published version of the manuscript.

Funding: This work was supported by the Genetically Modified Organisms Breeding Major Project of China (2019ZX08010004-004) and the National Natural Science Foundation of China (31901579).

Data Availability Statement: Data supporting reported results is available and provided at reasonable request.

Acknowledgments: We acknowledge the Department of Plant Breeding, University of Agriculture Faisalabad, Pakistan, to provide cotton genotypes used in the current study.

Conflicts of Interest: The authors declare no conflict of interest. 


\section{References}

1. Shahrajabian, M.H.; Sun, W.; Cheng, Q. Considering white gold, cotton for its fiber, seed oil, traditional and modern health benefits. J. Biol. Environ. Sci. 2020, 14, 25-39.

2. Lee, J.; Nadolnyak, D.A.; Hartarska, V.M. Impact of climate change on agricultural production in Asian countries: Evidence from panel study. In Proceedings of the Southern Agricultural Economics Association Annual Meeting, Birmingham, AL, USA, 4-7 February 2012.

3. Wahid, A.; Gelani, S.; Ashraf, M.; Foolad, M.R. Heat tolerance in plants: An overview. Environ. Exp. Bot. 2007, 61, 199-223. [CrossRef]

4. Echer, F.R.; Oosterhuis, D.M.; Loka, D.A.; Rosolem, C.A. High Night Temperatures During the Floral Bud Stage Increase the Abscission of Reproductive Structures in Cotton. J. Agron. Crop. Sci. 2014, 200, 191-198. [CrossRef]

5. Rafiq, A.; Iqbal, M.S.; Ibrar, D.; Mahmood, T.; Naveed, M.S.; Naeem, M.K. A review on heat stress response in different genotypes of tomato crop (Solanum lycopersicon L.). Int. J. Mod. Agric. 2013, 2, 64-71. [CrossRef]

6. El Sabagh, A.; Hossain, A.; Islam, M.S.; Barutcular, C.; Ratnasekera, D.; Gormus, O.; Amanet, K.; Mubeen, M.; Nasim, W.; Fahad, S.; et al. Drought and Heat Stress in Cotton (Gossypium hirsutum L.): Consequences and Their Possible Mitigation Strategies. In Agronomic Crops: Volume 3: Stress Responses and Tolerance; Hasanuzzaman, M., Ed.; Springer: Singapore, 2020 ; pp. 613-634.

7. Rizhsky, L.; Liang, H.; Shuman, J.; Shulaev, V.; Davletova, S.; Mittler, R. When Defense Pathways Collide. The Response of Arabidopsis to a Combination of Drought and Heat Stress. Plant Physiol. 2004, 134, 1683-1696. [CrossRef]

8. Saleem, M.A.; Malik, W.; Qayyum, A.; Ul-Allah, S.; Ahmad, M.Q.; Afzal, H.; Amjid, M.W.; Ateeq, M.F.; Zia, Z.U. Impact of heat stress responsive factors on growth and physiology of cotton (Gossypium hirsutum L.). Mol. Biol. Rep. 2021, 48, 1069-1079. [CrossRef] [PubMed]

9. Oosterhuis, D.M.; Snider, J.L. High temperature stress on floral development and yield of cotton. In Stress Physiology in Cotton; Oosterhuis, D.M., Ed.; The Cotton Foundation: Cordova, TN, USA, 2011; pp. 1-24.

10. Singh, R.P.; Prasad, P.V.; Sunita, K.; Giri, S.; Reddy, K.R. Influence of high temperature and breeding for heat tolerance in cotton: A review. Adv. Agron. 2007, 93, 313-385.

11. Xu, W.; Zhou, Z.; Zhan, D.; Zhao, W.; Meng, Y.; Chen, B.; Liu, W.; Wang, Y. The difference in the formation of thermotolerance of two cotton cultivars with different heat tolerance. Arch. Agron. Soil Sci. 2020, 66, 58-69. [CrossRef]

12. Dabbert, T.; Gore, M.A. Challenges and perspectives on improving heat and drought stress resilience in cotton. J. Cotton Sci. 2014, 18, 393-409.

13. Ozturk, M.; Hakeem, K.R.; Ashraf, M.; Ahmad, M.S.A. Crop Production Technologies for Sustainable Use and Conservation: Physiological and Molecular Advances; CRC Press: Boca Raton, FL, USA, 2019.

14. Iqbal, M.; Ul-Allah, S.; Naeem, M.; Ijaz, M.; Sattar, A.; Sher, A. Response of cotton genotypes to water and heat stress: From field to genes. Euphytica 2017, 213, 1-11. [CrossRef]

15. Farooq, A.; Shakeel, A.; Chattha, W.S.; Khan, T.M.; Azhar, M.T.; Saeed, A. Genetic variability in cotton germplasm: Predicting the agro physiological markers for high-temperature tolerance. J. Agric. Sci. 2021, 1-12. [CrossRef]

16. Sarwar, M.; Saleem, M.; Najeeb, U.; Shakeel, A.; Ali, S.; Bilal, M. Hydrogen peroxide reduces heat-induced yield losses in cotton (Gossypium hirsutum L.) by protecting cellular membrane damage. J. Agron. Crop. Sci. 2017, 203, 429-441. [CrossRef]

17. Liu, Z.; Yuan, Y.L.; Liu, S.Q.; Yu, X.N.; Rao, L.Q. Screening for high-temperature tolerant cotton cultivars by testing in vitro pollen germination, pollen tube growth and boll retention. J. Integr. Plant Biol. 2006, 48, 706-714. [CrossRef]

18. Conaty, W.; Burke, J.; Mahan, J.; Neilsen, J.; Sutton, B. Determining the optimum plant temperature of cotton physiology and yield to improve plant-based irrigation scheduling. Crop Sci. 2012, 52, 1828-1836. [CrossRef]

19. Lokhande, S.; Reddy, K.R. Quantifying temperature effects on cotton reproductive efficiency and fiber quality. Agron. J. 2014, 106, 1275-1282. [CrossRef]

20. Reddy, K.; Hodges, H.; Reddy, V. Temperature effects on cotton fruit retention. Agron. J. 1992, 84, 26-30. [CrossRef]

21. Wullschleger, S.D.; Oosterhuis, D.M. A rapid leaf-disc sampler for psychrometric water potential measurements. Plant Physiol. 1986, 81, 684-685. [CrossRef]

22. Cottee, N.; Tan, D.; Bange, M.; Cothren, J.; Campbell, L. Multi-level determination of heat tolerance in cotton (Gossypium hirsutum L.) under field conditions. Crop Sci. 2010, 50, 2553-2564. [CrossRef]

23. Zhang, J.; Zou, D.; Li, Y.; Sun, X.; Wang, N.-N.; Gong, S.-Y.; Zheng, Y.; Li, X.-B. GhMPK17, a cotton mitogen-activated protein kinase, is involved in plant response to high salinity and osmotic stresses and ABA signaling. PLoS ONE 2014, 9, e95642.

24. Kamal, M.; Saleem, M.; Shahid, M.; Awais, M.; Khan, H.; Ahmed, K. Ascorbic acid triggered physiochemical transformations at different phenological stages of heat-stressed Bt cotton. J. Agron. Crop. Sci. 2017, 203, 323-331. [CrossRef]

25. Kocsy, G.; Szalai, G.; Sutka, J.; Páldi, E.; Galiba, G. Heat tolerance together with heat stress-induced changes in glutathione and hydroxymethylglutathione levels is affected by chromosome 5A of wheat. Plant Sci. 2004, 166, 451-458. [CrossRef]

26. Roychoudhury, A.; Basu, S.; Sengupta, D.N. Antioxidants and stress-related metabolites in the seedlings of two indica rice varieties exposed to cadmium chloride toxicity. Acta Physiol. Plant. 2012, 34, 835-847. [CrossRef]

27. Suzuki, N.; Koussevitzky, S.; Mittler, R.; Miller, G. ROS and redox signalling in the response of plants to abiotic stress. Plant Cell Environ. 2012, 35, 259-270. [CrossRef]

28. Ali, B.; Iqbal, M.S.; Shah, M.K.N.; Shabbir, G.; Cheema, N.M. Genetic analysis for various traits in Gossypium hirsutum L. Pak. J. Agric. Res. 2011, 24, 8-13. 
29. Singh, S.; Vikram, P.; Sehgal, D.; Burgueño, J.; Sharma, A.; Singh, S.K.; Sansaloni, C.P.; Joynson, R.; Brabbs, T.; Ortiz, C.; et al. Harnessing genetic potential of wheat germplasm banks through impact-oriented-prebreeding for future food and nutritional security. Sci. Rep. 2018, 8, 12527. [CrossRef]

30. Azhar, F.; Ali, Z.; Akhtar, M.; Khan, A.; Trethowan, R. Genetic variability of heat tolerance, and its effect on yield and fibre quality traits in upland cotton (Gossypium hirsutum L.). Plant Breed. 2009, 128, 356-362. [CrossRef]

31. Gupta, P.; Langridge, P.; Mir, R. Marker-assisted wheat breeding: Present status and future possibilities. Mol. Breed. 2010, 26, 145-161. [CrossRef]

32. Mangi, N.; Nazir, M.F.; Wang, X.; Iqbal, M.S.; Sarfraz, Z.; Jatoi, G.H.; Mahmood, T.; Ma, Q.; Shuli, F. Dissecting Source-Sink Relationship of Subtending Leaf for Yield and Fiber Quality Attributes in Upland Cotton (Gossypium hirsutum L.). Plants 2021, 10, 1147. [CrossRef]

33. Jehanzeb Farooq, M.R.; Muhammad, A.; Muhammad, R.; Khalid, M.; Petrescu-Mag, V. Multivariate analysis for CLCuD and various morphological traits in some advanced lines of cotton Gossypium hirsutum L. Adv. Agric. Bot. Int. J. Bioflux Soc. 2015, 7, 241-247.

34. Singh, R.; Gupta, M. Multivariate analysis of divergence in upland cotton. Indian J. Genet. Plant Breed. 1968, 47, 11-14.

35. Rathinavel, K. Principal Component Analysis with Quantitative Traits in Extant Cotton Varieties (Gossypium Hirsutum L.) and Parental Lines for Diversity. Curr. Agric. Res. J. 2018, 6, 54-64. [CrossRef]

36. Bange, M.P.; Baker, J.T.; Bauer, P.J.; Broughton, K.J.; Constable, G.A.; Luo, Q.; Oosterhuis, D.M.; Osanai, Y.; Payton, P.; Tissue, D.T. Climate Change and Cotton Production in Modern Farming Systems; CABI: Oxfordshire, UK, 2016.

37. Jans, Y.; von Bloh, W.; Schaphoff, S.; Müller, C. Global cotton production under climate change-Implications for yield and water consumption. Hydrol. Earth Syst. Sci. 2020, 25, 2027-2044. [CrossRef]

38. Soviadan, M.K.; Koffi-Tessio, E.M.; Enete, A.A.; Nweze, N.J. Impact of Climate Change on Cotton Production: Case of Savannah Region, Northern Togo. Agric. Sci. 2019, 10, 927-947. [CrossRef]

39. Sousa, C.C.; Damasceno-Silva, K.J.; Bastos, E.A.; Rocha, M.M. Selection of cowpea progenies with enhanced drought-tolerance traits using principal component analysis. Genet. Mol. Res. 2015, 14, 15981-15987. [CrossRef]

40. Mohammadi, S.A.; Prasanna, B. Analysis of genetic diversity in crop plants-Salient statistical tools and considerations. Crop Sci. 2003, 43, 1235-1248. [CrossRef]

41. Muhammad, A.; Amir, S.; Khan, T.M.; Irfan, A. Genetic basis of variation for high temperature tolerance in upland cotton. Int. J. Agric. Biol. 2018, 20, 2637-2646.

42. Both, A.-J.; Benjamin, L.; Franklin, J.; Holroyd, G.; Incoll, L.D.; Lefsrud, M.G.; Pitkin, G. Guidelines for measuring and reporting environmental parameters for experiments in greenhouses. Plant Methods 2015, 11, 1-18. [CrossRef]

43. Velikova, V.; Yordanov, I.; Edreva, A. Oxidative stress and some antioxidant systems in acid rain-treated bean plants: Protective role of exogenous polyamines. Plant Sci. 2000, 151, 59-66. [CrossRef]

44. Liu, D.; Zou, J.; Meng, Q.; Zou, J.; Jiang, W. Uptake and accumulation and oxidative stress in garlic (Allium sativum L.) under lead phytotoxicity. Ecotoxicology 2009, 18, 134-143. [CrossRef] [PubMed]

45. Arnon, D.I. Copper enzymes in isolated chloroplasts. Polyphenoloxidase in Beta vulgaris. Plant Physiol. 1949, 24, 1. [CrossRef] [PubMed]

46. Gür, A.; Demirel, U.; Özden, M.; Kahraman, A.; Çopur, O. Diurnal gradual heat stress affects antioxidant enzymes, proline accumulation and some physiological components in cotton (Gossypium hirsutum L.). Afr. J. Biotechnol. 2010, 9, 1008-1015.

47. Majeed, S.; Malik, T.A.; Rana, I.A.; Azhar, M.T. Antioxidant and physiological responses of upland cotton accessions grown under high-temperature regimes. Iran. J. Sci. Technol. Trans. A Sci. 2019, 43, 2759-2768. [CrossRef]

48. Rana, R.; Khan, S.; Ali, Z.; Khan, A.; Khan, I. Elucidation of thermotolerance diversity in cotton (Gossypium hirsutum L.) using physio-molecular approaches. Genet. Mol. Res. 2011, 10, 1156-1167. [CrossRef] [PubMed]

49. Ali, S.; Khan, T.M.; Shakeel, A.; Saleem, M.F. Genetic basis of variation for physiological and yield contributing traits under normal and high temperature stress in Gossypium hirsutum L. Pak. J. Agric. Sci. 2020, 57, 1491-1501.

50. Joseph, B.; Jini, D.; Sujatha, S. Development of salt stress-tolerant plants by gene manipulation of antioxidant enzymes. Asian J. Agric. Res. 2011, 5, 17-27. [CrossRef]

51. Jiang, Y.; Huang, B. Drought and heat stress injury to two cool-season turfgrasses in relation to antioxidant metabolism and lipid peroxidation. Crop. Sci. 2001, 41, 436-442. [CrossRef]

52. Phung, T.-H.; Jung, S. Alterations in the porphyrin biosynthesis and antioxidant responses to chilling and heat stresses in Oryza sativa. Biol. Plant. 2015, 59, 341-349. [CrossRef]

53. Shu, S.; Yuan, L.-Y.; Guo, S.-R.; Sun, J.; Yuan, Y.-H. Effects of exogenous spermine on chlorophyll fluorescence, antioxidant system and ultrastructure of chloroplasts in Cucumis sativus L. under salt stress. Plant Physiol. Biochem. 2013, 63, 209-216. [CrossRef]

54. Chalanika De Silva, H.C.; Asaeda, T. Effects of heat stress on growth, photosynthetic pigments, oxidative damage and competitive capacity of three submerged macrophytes. J. Plant Interact. 2017, 12, 228-236. [CrossRef]

55. Chapepa, B.; Mubvekeri, W.; Mare, M.; Kutywayo, D. Correlation and path coefficient analysis of polygenic traits of upland cotton genotypes grown in Zimbabwe. Cogent Food Agric. 2020, 6, 1823594. [CrossRef]

56. Khalid, H.; Khan, I.A.; Sadaqat, H.A.; Muhammad, A. Genotypic and phenotypic correlation analysis of yield and fiber quality determining traits in upland cotton (Gossypim hirsutum). Int. J. Agric. Biol. 2010, 12, 348-352.

57. Malik, T.A. Correlation for economic traits in upland cotton. ACTA Sci. Agric. 2018, 2, 59-62. 
58. Chunthaburee, S.; Dongsansuk, A.; Sanitchon, J.; Pattanagul, W.; Theerakulpisut, P. Physiological and biochemical parameters for evaluation and clustering of rice cultivars differing in salt tolerance at seedling stage. Saudi J. Biol. Sci. 2016, 23, 467-477. [CrossRef] [PubMed]

59. Jamil, A.; Khan, S.J.; Ullah, K. Genetic diversity for cell membrane thermostability, yield and quality attributes in cotton (Gossypium hirsutum L.). Genet. Resour. Crop. Evol. 2020, 67, 1405-1414. [CrossRef]

60. Saeed, F.; Shabbir, R.H.; Farooq, J.; Riaz, M.; Mahmood, K. Genetic Diversity Analysis for Earliness, Fiber Quality and Cotton Leaf Curl Virus in Gossypium hirsutum L. Accessions. Cotton Genom. Genet. 2015, 6, 1-7.

61. Shabbir, R.H.; Bashir, Q.A.; Shakeel, A.; Khan, M.M.; Farooq, J.; Fiaz, S.; Ijaz, B.; Noor, M.A. Genetic divergence assessment in upland cotton (Gossypium hirsutum L.) using various statistical tools. J. Glob. Innov. Agric. Soc. Sci. 2016, 4, 62-69. [CrossRef]

62. Amna, N.; Jehanzeb, F.; Abid, M.; Muhammad, S.; Muhammad, R. Estimation of genetic diversity for CLCuV, earliness and fiber quality traits using various statistical procedures in different crosses of Gossypium hirsutum L. Вестник Аграрной Науки 2013, 43, 2-9.

63. Isong, A.; Balu, P.A.; Ramakrishnan, P. Association and principal component analysis of yield and its components in cultivated cotton. Electron. J. Plant Breed. 2017, 8, 857-864. [CrossRef]

64. Javed, M.; Hussain, S.; Baber, M. Assessment of genetic diversity of cotton genotypes for various economic traits against cotton leaf curl disease (CLCuD). Genet. Mol. Res. 2017, 16, 1-12. [CrossRef] 